\title{
Feeding Pattern and Nutritional Status of Under Two Years Slum Children
}

\author{
Akhtar $\mathrm{K}^{1}$, Haque $\mathrm{ME}^{2}$, Islam $\mathrm{MZ}^{3}$, Yusuf $\mathrm{MA}^{4}$, Sharif $\mathrm{AR}^{5}$, Ahsan $\mathrm{AI}^{6}$
}

\begin{abstract}
Background: Feeding practices play a pivotal role in determining the optimal development of infants. Through this study the information helps to make planning to decrease malnutrition and way of proper feeding in reaching the target of MDG 4. Objective: The aim of the's present study was to assess feeding pattern and nutritional status of under two years children. Methodology: This cross sectional descriptive study was carried out in one slum of Dhaka City Corporation from January to June 2010. The study included 125 apparently healthy children and their mothers as respondents. Result: Among all the mothers 120 (96\%) respondents fed their child colostrum; $54(45.0 \%)$ respondents initiated breastfeeding within one hour of birth.105 (84\%) respondents gave prelacteal feeding. only $20(16 \%)$ respondents practiced exclusive breastfeeding for 6 months. It was revealed that $80(64 \%)$ mothers fed their child complementary feeding at the age 6-7 months. Nutritional status of the children was in $-<3$ SD including $17.4 \%$ stunting, $19.1 \%$ wasting and $24.3 \%$ underweight. Conclusion: Traditional cultural barriers is still existed with poor practice of exclusive breast feeding while complementary feeding pattern had bizarre pattern.
\end{abstract}

Key words: Feeding pattern, slum children, nutritional status

\section{Introduction}

As a global public health recommendation, infants should be exclusively breastfed for the first six months of life to achieve optimal growth, development and health ${ }^{1}$. Thereafter, to meet their evolving nutritional requirements, infants should receive nutritionally adequate and safe complementary foods while breastfeeding continues for upto two years of age or beyond ${ }^{2}$.

The baby should receive the breastfed as soon as possible and preferably within half an hour of birth ${ }^{2}$. Overall, $43 \%$ of children are breastfed within one hour, and $89 \%$ are breastfed within one day after delivery ${ }^{1}$. Late initiation of breastfeeding is a reason for introducing pre-lacteal feeding ${ }^{2}$. More than six in ten newborns $(62 \%)$ receive a pre-lacteal feeding. Recent WHO studies estimate that death rate in babies can go down four times if they are exclusively breastfed for the first six months ${ }^{2}$. The risk of death from diarrhoeal diseases and pneumonia is 14 and 4 times higher in bottle-fed infant in developing countries respectively compared to infants exclusively breastfed for the first 4-6 months of their lives ${ }^{3}$. Although the prevalence of breastfeeding is very high in Bangladesh, it is almost $98 \%$ but appropriate breastfeeding is rarely practiced ${ }^{1}$.
Complementary feeding is extremely essential and typically covers the period from 6 to 18-24 months of age. WHO recommend introducing complementary feeding only from the seventh month on- wards ${ }^{4}$. Malnutrition has been responsible, directly or indirectly, for $60 \%$ of the 10.9 million deaths annually among children under five. Well over two-thirds of these deaths, which are often associated with inappropriate feeding practices, occur during the first

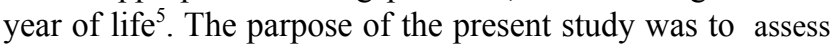
feeding pattern and nutritional status of under two years children.

\section{Materials and Methods}

A community based cross-sectional descriptive study was conducted during January-June 2010 to find out the feeding pattern and nutritional status of under two years children. Data was collected from slum near Basundhara residential area under Dhaka City Corporation and the study population were apparently healthy child aged between 6 to 23 months. In total, 125 children aged two years were selected purposively. Data were collected through face to face interview of the respondents using pretested semi-structured questionnaire and checklist. Length measuring scalewooden measuring board (Infantometer) and Weight machine-bathroom scale were used for estimation of length and weight of the children. Data was cleaned, verified and

1. Dr. Khursheda Akhtar, Lecturer, Department of Community Medicine, Shaheed Shurawardy Medical College, Dhaka

2. Prof. Dr. Md. Emdadul Haque, Head, Department of Nutrition and Biochemistry, National Institute of Preventive \& Social Medicine, Dhaka

3. Dr. Md. Ziaul Islam, Associate Professor, Department of Community Medicine, National Institute of Preventive \& Social Medicine, Dhaka

4. Dr. Md. Abdullah Yusuf, Lecturer, Department of Microbiology, Shaheed Shurawardy Medical College, Dhaka

5. Dr. Ahmad Raihan Sharif, Medical Officer, Department of Virology, Institute of Epidemiology, Disease Control \& Research (IEDCR), Dhaka

6. Dr. Ali Imam Ahsan, Junior Consultant, Society for Assistance to Hearing Impaired Children (SAHIC). Dhaka

\section{Correspondence}

Dr. Khursheda Akhtar, Lecturer, Department of Community Medicine, Shaheed Shurawardy Medical College, Sher-E-Bangla Nagar Dhaka, Email : mukta1972@yahoo.com, Mobile : +8801714712174 
edited if there were any discrepancy. The frequency distributions of the entire variables were checked by using SPSS 17.0 window program. During data analysis the raw anthrometric data of SPSS 17.0 were transferred to Anthro2005 to obtain derived indices of anthropometric measurements such as Weight for age $Z$ scores (WAZ), Height for age $\mathrm{Z}$ score (HAZ) and Weight for height $\mathrm{Z}$ score (WHZ). The indices obtained from Anthropometry 2005 were then transferred again to the SPSS17.0 windows for further analysis. For tabular chart and graphical representation Microsoft word and Microsoft Excel were used.

\section{Results}

Out of total 125 mothers as respondents 120 (96\%) mothers fed their child colostrum while only 5(4\%) mother didn't fed their children colostrum (Figure-1).

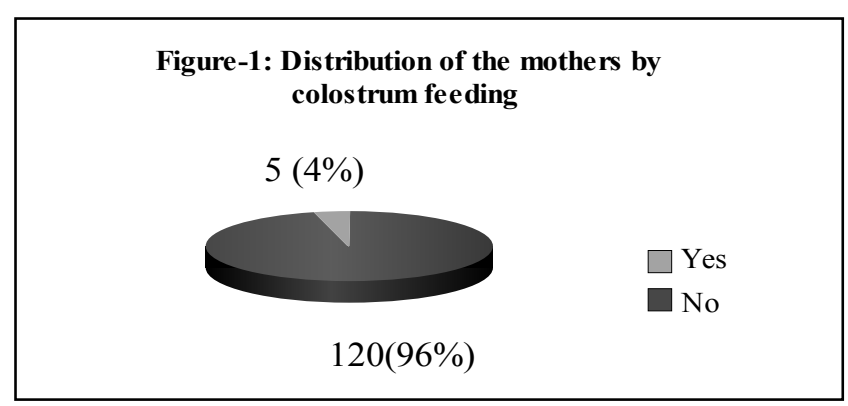

Majority of the mothers $(45.0 \%)$ started breast feeding to their children within one hour of birth, and other relevant finding are shown in the Table-1.

Table1: Timing of initial breastfeeding: $n=120$

\begin{tabular}{lcc}
\hline $\begin{array}{l}\text { Time of initial } \\
\text { breastfeeding }\end{array}$ & Frequency & Percentage \\
\hline Within one hour & 54 & 45.0 \\
1-2 hour & 42 & 35.0 \\
3-4 hour & 13 & 10.8 \\
More than 4 hour & 11 & 9.2 \\
Total & $\mathbf{1 2 0}$ & $\mathbf{1 0 0 . 0}$ \\
\hline
\end{tabular}

Most of the mothers (84\%) fed their child pre lacteal feeding while $31(29.5 \%)$ mothers fed their children honey

Table-2: Type of prelacteal feeding $(n=105)$

\begin{tabular}{lcc}
\hline Type of prelacteal food & Frequency & Percentage \\
\hline Honey & 31 & 29.5 \\
Water & 13 & 12.4 \\
Formula milk & 6 & 5.7 \\
Sugar water & 31 & 29.5 \\
Cow's milk & 4 & 3.8 \\
Water and formula milk & 3 & 2.9 \\
Honey, sugar water & 15 & 14.3 \\
Honey, cow's milk & 2 & 1.9 \\
Total & $\mathbf{1 0 5}$ & $\mathbf{1 0 0 . 0}$ \\
\hline
\end{tabular}

and sugar water separately. Other most common feeding are shown in the table-2. Regarding exclusive breastfeeding,

\begin{tabular}{|l|}
\hline $\begin{array}{c}\text { Figure-2: Distribution of the mothers by } \\
\text { exclusive breastfeeding }\end{array}$ \\
$20(16 \%)$ \\
$105(84 \%)$ \\
$\square$ Nos \\
\\
\end{tabular}

$20(16 \%)$ mother exclusively breastfed their children but most of them (84\%) mothers didn't exclusively breastfed their child. (Figure-2). Majority of the mothers (64\%) started complementary feeding at 6-7 months while $24(19.2 \%)$ started at 4-5 months and others shown in the Table-3.

Table-3: Initiation of complementary feeding

\begin{tabular}{lcc}
\hline $\begin{array}{l}\text { Initiation of complementary } \\
\text { feeding }\end{array}$ & Frequency & Percentage \\
\hline 2-3 months & 3 & 2.4 \\
4-5 months & 24 & 19.2 \\
6-7 months & 80 & 64.0 \\
More than 7 months & 18 & 14.4 \\
Total & $\mathbf{1 2 5}$ & $\mathbf{1 0 0 . 0}$ \\
\hline
\end{tabular}

In respect of types of complementary feeding, maximum mothers $(36.8 \%)$ fed their children family food, followed by rice powder with milk $(33.6 \%) \& 25(20.0 \%)$ respondents fed their child khichuri, and other are shown in the Table-4. Considering overall nutritional status out of 125 children, complete and plausible anthrometric data of 115 children aged 6-23 months were collected.

\section{Discussion}

Sample is presented as pattern of breastfeeding, relating colostrum feeding; in this study most of the respondents (96\%) fed their child colostrum. According to BDHS 2007 it was $92 \%$ which was similar to the national survey. The likelihood of a child receiving colostrum increases with mothers' education by increasing awareness regarding colostrum feeding ${ }^{3}$.

Regarding initiation of breastfeeding most of the respondent $(45.0 \%)$ initiate breastfeeding within one hour, $35.0 \%$ mothers fed their child between 1 to 2 hour. Summation of all initiation of breastfeeding it assumed that $96 \%$ respondents fed their children colostrum within one day after birth. According to BDHS 2007, it was shown that $89 \%$ were breastfed within one day after delivery ${ }^{1}$. 
Maximum respondent (84\%) fed their child prelacteal feeding. Out of ten, more than eight mothers fed their child prelacteal feeding in national data it is $62 \%$ more than six in ten. Most of the respondents (29.5\%) fed their child honey and sugar water separately, followed by plain water (12.4\%), formula milk (5.7\%) only cow's milk fed by $3.8 \%$ Prelacteal feeding is widely practiced in Bangladesh. Vast majority like $80 \%$ said honey $9 \%$ of mother said sugar water ${ }^{6}$.

Table-4: Type of complementary feeding

\begin{tabular}{lcc}
\hline $\begin{array}{l}\text { Type of complementary } \\
\text { feeding }\end{array}$ & Frequency & Percentage \\
\hline Barley & 2 & 1.6 \\
Biscuit & 2 & 1.6 \\
Cerelac & 2 & 1.6 \\
Family food & 46 & 36.8 \\
Kichuri & 25 & 20.0 \\
Noodles & 2 & 1.6 \\
Powder milk & 4 & 3.2 \\
Rice with milk & 42 & 33.6 \\
Total & $\mathbf{1 2 5}$ & $\mathbf{1 0 0 . 0}$ \\
\hline
\end{tabular}

It is shown that only $20(16 \%)$ respondents exclusively breastfed their child; rest of the respondents not exclusively breastfed their child. The prevalence of exclusive breastfeeding was very low. In NNP baseline survey showed a rate of exclusive breast feeding $(12.8 \%)$ until six months of age. Another study from ICDDR,B reported the prevalence of exclusive breastfeeding to be $15 \%$ only $^{3}$. Those babies who had taken prelacteal feeding were excluded from exclusive breastfeeding criteria.

Regarding initiation of complementary feeding maximum (64\%) respondents gave their child complementary feeding between 6-7 months. Maximum child were started complementary feeding timely.

Table-5 Distribution of nutritional status of under two years slum children

\begin{tabular}{|c|c|c|}
\hline Nutritional status & Parameter & Percentage \\
\hline \multirow{2}{*}{$\begin{array}{l}\text { Height for age } \\
\text { (Stunting) }\end{array}$} & Perc entage below -2SD & 42.60 \\
\hline & Percentage below $-3 \mathrm{SD}$ & 17.40 \\
\hline \multirow{2}{*}{$\begin{array}{l}\text { Weight for height } \\
\text { (wasting) }\end{array}$} & Percentage below $-2 \mathrm{SD}$ & 36.50 \\
\hline & Percentage below $-3 \mathrm{SD}$ & 19.10 \\
\hline \multirow{2}{*}{$\begin{array}{l}\text { Weight for age } \\
\text { (Under weight) }\end{array}$} & Percentage below -2SD & 55.70 \\
\hline & Percentage below -3SD & 24.30 \\
\hline
\end{tabular}

Regarding type of complementary feeding maximum respondents $(36.8 \%)$ fed their child with family food. Due to poverty family food were affordable for them. Next of them $42(33.6 \%)$ respondents fed rice gruel with milk powder, 25
(20.0\%) respondents fed their child kichuri .In present study, more than seven month of age group child were fed family food as primary complementary food. Family foods were rice, lentil and vegetables which were commonly practiced. Among 46 children those who take family food only five $(10.87 \%)$ children were fed with fish, meat or egg. Out of ten nearly one child was given meat, fish, poultry or egg.

To evaluate the prevalence of under nutrition, in the study almost more than half of the children under two years age $55.7 \%$ were under weight and $42.6 \%$ were stunted and $36.5 \%$ were wasted. The proportion of children who were severely undernourished was also note able $-<3$ SD including $17.4 \%$ stunting, $19.1 \%$ wasting and $24.3 \%$ underweight. Countrywide data for the prevalence of malnutrition in urban slums under two year children are lacking. Under nutrition are more in rural to urban. But prevalence of under nutrition was more in slum area than rural or all urban? Another study in Chittagong Hill Tract showed that the prevalence of underweight was $56 \%$ and stunting $48 \%{ }^{8}$. In other study in Chittagong slum it was showed that it was 45$58 \%$ followed by Khulna slum (40-50\%) and Dhaka slum $(29-41 \%)^{9}$. In a study from India it was shown that the overall prevalence of underweight, stunting and wasting was $63.7 \%, 47.85 \%$ and $32.7 \%$ respectively ${ }^{10}$. It indicates that the children of under two years were in critical nutritional stress. Addressing nutritional problems of urban poor is therefore most for overall development of the country.

\section{Conclusion}

The study was permited to conclude that the rate of early initiation of breastfeeding like colostrum was improved but prevalence of pre-lacteal feeding was still high which was harmful for the children. The percentage of exclusive breastfeeding was very low which was far away from acceptable range. Mother or caregivers should have proper knowledge regarding nutritive value of foods and ways to provide nutrition to their child.

\section{References}

1. Ministry of Health and Family Welfare .National Institute of Population Research and Training (NIPORT), Bangladesh Demographic and Health Survey 2007. Dhaka, Bangladesh.

2. Ministry of Human Resource Development, Department of Women and Child Development, Food and Nutrition Board, Government of India. National Guidelines on Infant and Young Child Feeding 2004

3. Faruque ASG, Ahmed AMS, Ahmed T, Islam MM, Hossain IM, Roy SK, et al. Nutrition: Basis for Healthy Children and Mother in Bangladesh. JPHN .2008Sep; 26(3): 325-39

4. Agostoni C, Decsi T, Fewtrell M, Goulet O, Kolacek S, Koletzko B, et al. Complementary feeding: A commentary by the ESPGHAN committee on Nutrition. J Pediatr Gastroentrol Nutr 2008 Jan; Vol.46(1): 5. World Health Organization .Global strategy for infant and young

child feeding [A55/15, Annex -16 April 2002], Annex 2, WHO.

6. Roy SK. Complementary Feeding in South Asia, ICDDR'B, Page54, [Web site: http://www.icddrb,org/publication]

7. Comparison of Malnutrition in Dhaka Slum, Total Urban and Rural areas of Bangladesh. (1999 data*Slum data age group .5-4.99; total 
urban and rural 0-4.99).1999

8. Akhter N, Torlesse H, Pee Sde, Ibrahim QIU ,Stallkamp G, Panagides D, Bloem MW. Nutritional Status of Young Children and Their Mothers in Chittagong Hill Tracts, Bangladesh.2003 Dec;P57(172). [Web site: http://www.icddrb,org/publication]

9. Ibrahim QIU, Akhter N, Chowdhury T, Torlesse H, Stallkamp G, Panagides D. et al. Assessment of Nutrition and Health Status in Slumsof Dhaka, Khulna, and Chittagong, Bangladesh. 2003 Dec; P56 (171). [Web Site: http://www.icddrb,org/publication]

10. Bisai S, Bose K, Dikshit S. Under-nutrition among slum children aged 3-6 years in Midnapore town, India. The Internet Journal of BiologicalAnthropology 2009; 2 (2): 26-29 